\title{
Implementing eScreening technology in four VA clinics: a mixed-method study
}

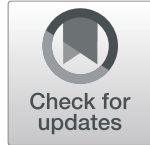

James O. E. Pittman ${ }^{1,2^{*}}$ (D), Niloofar Afari ${ }^{1,2}$, Elizabeth Floto ${ }^{3}$, Erin Almklov', Susan Conner ${ }^{4}$, Borsika Rabin ${ }^{1,5}$ and Laurie Lindamer ${ }^{1,2}$

\begin{abstract}
Background: Technology-based self-assessment (TB-SA) benefits patients and providers and has shown feasibility, ease of use, efficiency, and cost savings. A promising TB-SA, the VA eScreening program, has shown promise for the efficient and effective collection of mental and physical health information. To assist adoption of eScreening by healthcare providers, we assessed technology-related as well as individual- and system-level factors that might influence the implementation of eScreening in four diverse VA clinics.
\end{abstract}

Methods: This was a mixed-method, pre-post, quasi-experimental study originally designed as a quality improvement project. The clinics were selected to represent a range of environments that could potentially benefit from TB-SA and that made use of the variety eScreening functions. Because of limited resources, the implementation strategy consisted of staff education, training, and technical support as needed. Data was collected using pre- and post-implementation interviews or focus groups of leadership and clinical staff, eScreening usage data, and post-implementation surveys. Data was gathered on: 1) usability of eScreening; 2) knowledge about and acceptability and 3) facilitators and barriers to the successful implementation of eScreening.

Results: Overall, staff feedback about eScreening was positive. Knowledge about eScreening ranged widely between the clinics. Nearly all staff felt eScreening would fit well into their clinical setting at pre-implementation; however some felt it was a poor fit with emergent cases and older adults at post-implementation. Lack of adequate personnel support and perceived leadership support were barriers to implementation. Adequate training and technical assistance were cited as important facilitators. One clinic fully implemented eScreening, two partially implemented, and one clinic did not implement escreening as part of normal practice after 6 months as measured by usage data and self-report. Organizational engagement survey scores were higher among clinics with full or partial implementation and low in the clinic that did not implement.

Conclusions: Despite some added work load for some staff and perceived lack of leadership support, eScreening was at least partially implemented in three clinics. The technology itself posed no barriers in any of the settings. An implementation strategy that accounts for increased work burden and includes accountability may help in future eScreening implementation efforts.

Note. This abstract was previously published (e.g., Annals of Behavioral Medicine 53: S1-S842, 2019).

Keywords: Technology, Health information technology, eScreening, Implementation, Veterans, Mixed methods

\footnotetext{
* Correspondence: james.pittman@va.gov

'VA Center of Excellence for Stress and Mental Health, 3350 La Jolla Village

Dr., San Diego, CA 92161, USA

2Department of Psychiatry, University of California San Diego, 9500 Gilman

Dr, La Jolla, CA 92093, USA

Full list of author information is available at the end of the article
}

(c) The Author(s). 2019 Open Access This article is distributed under the terms of the Creative Commons Attribution 4.0 International License (http://creativecommons.org/licenses/by/4.0/), which permits unrestricted use, distribution, and reproduction in any medium, provided you give appropriate credit to the original author(s) and the source, provide a link to the Creative Commons license, and indicate if changes were made. The Creative Commons Public Domain Dedication waiver (http://creativecommons.org/publicdomain/zero/1.0/) applies to the data made available in this article, unless otherwise stated. 


\section{Background}

The use of health information technology (HIT) to support the provision of health care is rapidly increasing $[1,2]$; yet, the evidence regarding its effect on patient outcomes is mixed [3]. There is, however, a growing body of literature supporting the use of technology to automate patient self-report health screening [4-8].

Computerized self-assessments have been successfully introduced in a variety of populations, including older adults with and without cognitive impairment [9-11], pregnant women [12], and youth [13]. Feasibility of using technology for the collection of patient-reported data has been demonstrated in many medical and psychiatric disorders [8, 13-17]. The utility of technologybased assessment is robust across numerous settings, such as hospitals, community clinics, outpatient clinics, home, and in clinical trials $[6,18,19]$. Computer-based self-assessment has been shown to have benefits for patients, providers, and systems and has shown feasibility, ease of use, efficiency, and cost savings [11, 20-26]. Thus, tablet-based self-assessments, which have the added benefits of portability and accessibility, have the potential to increase access to and the quality of healthcare.

Serving over 9 million veterans each year [27], the Veterans Administration (VA) has developed several technology-based solutions to improve the delivery of healthcare to its growing population [28-33]. The VA Center of Excellence for Stress and Mental Health (CESAMH) and VA Center for Innovation (VACI) developed the eScreening program. The eScreening program is a technology-based, self-screening tool that has shown promise for the efficient and effective collection of mental and physical health information in healthcare clinics that collect self-report data to triage care [23]. It is a web-based program designed to collect Veteran selfreport information and standardized screens, such as the posttraumatic stress disorder checklist (PCL-5); alert clinicians to safety concerns; read and write to the electronic medical record; and provide veterans with personalized feedback. It is designed to tailor assessments to the specific needs of the clinic. A pilot study that compared eScreening to paper screening with post-9/11 veterans in the transition care management program found that eScreening improved accessibility, rate of screening completion, and some clinical processes, and both veterans and providers indicated satisfaction with the tablet-based assessment [23].

Despite the significant need and ample support for technology-based solutions to aid health care delivery, implementation of HIT has been challenging [34-37]. Challenges include the complex nature of technologybased interventions and the health care delivery context as well as limited understanding of what mechanisms and contextual factors influence adoption and implementation. To assist in the future implementation and scale-up of eScreening, we conducted a mixed method, quality improvement project (QIP) of the implementation of eScreening in a diverse set of clinical environments in four VA clinics using the Consolidated Framework for Implementation Research (CFIR) as a guide to identify relevant implementation constructs. We assessed leadership and clinical staff regarding technology-related, as well as individual- and system-level factors, that might influence the adoption and implementation of the eScreening intervention. The purpose was to gather information on: (1) implementation of eScreening; (2) knowledge about and acceptability, perceived fit/adaptability, and relative advantage of using eScreening; (3) usability of eScreening; and (4) facilitators and barriers to successful implementation of eScreening including system and organizational readiness and resources.

\section{Method}

This was a mixed-method, pre-post quasi-experimental study related to eScreening implementation in four clinics at the VA San Diego Healthcare System (VASDHS) that was conducted as part of a QIP. The main objective of the QIP was to implement eScreening in four diverse clinic settings with input from frontline clinical staff and leadership.

\section{Contracted agency}

VASDHS contracted Gallup Inc., an organization that provides research and analytics to help measure, monitor, and improve outcomes for government and nongovernment partners. Gallup has expertise in linking employee opinions and beliefs to the successful implementation of new processes and procedures. Gallup staff (co-author SC) was involved in the development of the interview guides, conducted all interviews and focus groups, collected quantitative survey data, completed analyses, and provided written data summaries.

\section{Participating clinics}

The four VASDHS clinics were selected to represent a range of environments that could potentially benefit from technology-assisted data collection and from the variety of eScreening functions. Clinics widely differed on many factors, including type of services provided, goal for eScreening use, size and organization, and work flow and volume. The clinics, described in Table 1, included: 1) Transition Care Management (TCM), 2) Primary Care (PC), 3) Posttraumatic Stress Disorder (PTSD), and 4) Mental Health Access (MHA). TCM provides comprehensive screening for Veteran's enrolling for healthcare. Primary Care provides ongoing general 
Table 1 Participating Clinics

\begin{tabular}{|c|c|c|c|c|c|c|c|}
\hline Clinic & Type & Goal & Appointment & Patient Type & Provider type & $\begin{array}{l}\text { When eScreening } \\
\text { occurred }\end{array}$ & $\begin{array}{l}\text { Person overseeing } \\
\text { eScreening }\end{array}$ \\
\hline TCM & $\begin{array}{l}\text { VHA } \\
\text { Enrollment }\end{array}$ & $\begin{array}{l}\text { Demo, medical and } \\
\text { admin data; Triage }\end{array}$ & Walk-in & $\begin{array}{l}\text { Post-9/11 } \\
\text { Veterans }\end{array}$ & Social work providers & $\begin{array}{l}\text { Waiting for } \\
\text { appointment }\end{array}$ & Social work \\
\hline PC & $\begin{array}{l}\text { Medical } \\
\text { Care }\end{array}$ & $\begin{array}{l}\text { Medical data; } \\
\text { Clinical reminders }\end{array}$ & Scheduled & All era Veterans & Physicians, nurses & Prior to appointment & Admin staff \\
\hline PTSD & $\begin{array}{l}\text { Specialty } \\
\text { MH Care }\end{array}$ & Symptom severity & Scheduled & $\begin{array}{l}\text { All era Veterans/ } \\
\text { w PTSD }\end{array}$ & Psychologists & $\begin{array}{l}\text { Prior to and during } \\
\text { appointment }\end{array}$ & $\begin{array}{l}\text { Admin staff and } \\
\text { providers }\end{array}$ \\
\hline MHA & $\begin{array}{l}\text { Urgent MH } \\
\text { Care }\end{array}$ & Symptom severity; Triage & Walk-in & $\begin{array}{l}\text { All era Veterans } \\
\text { in } \mathrm{MH} \text { crisis }\end{array}$ & $\begin{array}{l}\text { Psychiatrist and social } \\
\text { work provider }\end{array}$ & $* *$ & $* *$ \\
\hline
\end{tabular}

Note: Admin Administrative, Demo Demographic, MH Mental Health, MHA Mental Health Access, PC Primary Care, PTSD Post Traumatic Stress Disorder, TCM Transition Care Management, VHA Veterans Health Administration, ** No eScreening completed

healthcare, PTSD provides evidence based psychotherapy treatment for trauma-related disorders, and MHA provides same day urgent walk-in clinic for mental health patients.

\section{Implementation strategy}

This study began as a QIP with limited resources to support the implementation process. Therefore, the implementation strategy consisted of one eScreening education meeting and one hands-on training session followed by ongoing technical assistance upon request. During the education session, our implementation team provided a general overview of eScreening and the processes involved, discussed the potential benefits to staff and patients, and answered staff questions. During the second meeting, we provided hands-on training with the eScreening program using test patients. During the technical assistance sessions, we addressed more specific individual problems and concerns. All staff involved in using eScreening in each clinic were trained. In consultation with staff leadership, the types and number of assessments were selected to meet the particular needs of the clinic. In person, telephone, and email technical assistance was provided when requested throughout the implementation period by the eScreening support staff, but no data on the nature and amount of contact the eScreening team had with each clinic was collected due to resource limitations. The duration of the implementation period was 17 months, from September 2014 through January 2016.

\section{Data collection}

Leadership and non-leadership staff from each VASDHS clinic were invited to participate in interviews or focus groups, respectively, led by Gallup staff. Individual interviews were conducted with leadership to accommodate schedules. Focus groups were conducted separately for all staff in each clinic at a time intended to maximize participation of all clinic positions (e.g., health providers, nursing, and administrative staff). Gallup conducted fourteen 30-min interviews with leadership and three 60-min pre-implementation focus groups with non-leadership personnel and across TCM, PC, PTSD, and MHA clinics in July 2014. They conducted twelve 45-min post-implementation interviews with leadership and four 90-min post-implementation focus groups with ten non-leadership personnel in February 2016. All interviews and focus groups were audio recorded.

Implementation outcomes were measured by usage and survey data. The number of eScreening assessments completed by each program during the 6 months after implementation was extracted from the eScreening system. Self-report level of implementation was collected via the eScreeening survey.

In addition to the focus groups, Gallup collected survey data from non-leadership staff post-implementation. After post-implementation focus groups were conducted non-leadership staff was given a unique identifier and access code to take an anonymous online web survey. Staff had 2 weeks to complete the online survey.

\section{Instruments}

The interview guides (see Additional files 1, 2, 3 and 4) for the individual and focus group interviews were developed using the Consolidated Framework for Implementation Research (CFIR) [38]. CFIR is a broadly used, comprehensive implementation science model that includes constructs associated with successful implementation in the literature. In our interview guide we focused on the inner and outer setting, with questions such as, "Tell me how leadership has communicated that changes made today to implement eScreening will affect the organization in the future?" and "How will veterans adapt to the new process?". We also asked questions related to the characteristics of intervention and individual domains of CFIR such as, "What is the first thing that comes to your mind when you hear the term eScreening?"; "What are your expectations for eScreening?"; and "I use eScreening in the clinic". The online survey was a combination of the Gallup Employee Engagement Survey $\left(\mathrm{Q} 12^{\circ}\right)$ and an eScreening-specific survey. The $\mathrm{Q} 12^{\circ}$ is regularly used by Gallup to measure employee 
engagement and has been validated to predict workplace performance [39]. The $\mathrm{Q} 12^{\circ}$ contains 12 items that measure employees' basic needs (expectations and materials and equipment), individual-level factors (accomplishment, recognition, importance and development), team-level items (contribution, mission, connection, and work ethic) and opportunity for growth and progress [39]. Each of the 12 items are scored on a Likert scale (1-5, strongly disagree to strongly agree), analyzed separately, and then combined for "Engagement" and "Satisfaction" scores. The means are compared to a relevant normative group (Government Workgroup-Level database) to determine percentiles for comparison.

An investigator-created, eScreening-specific 9-item survey assessed confidence in leadership, staff ability to adapt to changes, opinions about training, concerns about technical issues, perception of barriers, satisfaction with the implementation process, and eScreening use. Each item was scored individually on a Likert scale (1-5, strongly disagree to strongly agree). Item examples include: "Technical issues or problems with eScreening were resolved quickly" and "I am satisfied with the eScreening implementation process in the clinic".

\section{Data analysis}

Pre- and post- implementation focus groups and individual interviews were recorded and transcribed verbatim. A Gallup staff member, who is also a co-author (SC), analyzed the data to identify common concepts and themes that emerged from the CFIR-informed interview guide. Domains were selected a priori and focused on inner and outer setting and characteristics of intervention and individuals. Reports of summarized findings and recommendations by CFIR domain and clinic group (post-implementation only) were prepared. These data were further analyzed by the investigators (LL, JP, BR) and categorized once consensus was achieved according to the project aims: knowledge about and acceptability, perceived fit/adaptability, and relative advantage of using eScreening; usability of eScreening; and facilitators and barriers to successful implementation of eScreening, including system and organizational readiness and resources.

Descriptive analyses of the $\mathrm{Q} 12^{\circ}$ data collected were performed using Gallup's proprietary software to yield mean scores for each clinic for the 12 individual survey items and the "Engagement" and "Satisfaction" subscales. The means were compared to a relevant normative group (Government Workgroup-Level database) to determine percentiles for comparison. Higher percentile scores are associated with stronger performance, such as increased productivity. Descriptive analyses of the eScreening specific questionnaire were calculated to compare means for each item by clinic.
In order to compare results of qualitative and quantitative data in combination, the pre-post qualitative results were categorized as either positive, mostly positive, mixed, mostly negative, or negative. The quantitative and qualitative data were cross tabulated to assess for congruence or difference.

\section{Results \\ Participants}

To ensure anonymity in this relatively small sample, demographic characteristics of leadership staff beyond their organizational role were not collected. In the preimplementation interviews and focus groups of nonleadership participants, there were 10 licensed independent providers, 9 nurses, and 13 medical support staff. There were 9 pre-implementation interviews with leadership. Post-implementation interviews and focus groups consisted of all non-leadership personnel and included 13 licensed independent providers, 5 nurses, and 16 medical support staff.

\section{Implementation of eScreening}

The number of eScreening assessments collected over the 6 months post-implementation was 1026 for TCM, 337 for PTSD, and 113 for PC clinics. The MHA clinic conducted no screening assessments. On the study-specific survey, clinics rated their use of eScreening on a scale of $1-5$, with higher scores indicating greater use. The TCM clinic reported the highest level of use $(\mathrm{M}=$ $4.5, \mathrm{SD}=.58)$, followed by PTSD $(\mathrm{M}=3.8, \mathrm{SD}=.84)$, and $\mathrm{PC}(\mathrm{M}=3.6, \mathrm{SD}=1.15)$. Clinics self-report of degree of implementation of eScreening were consistent with the number of tablet-based assessments completed. These two data sources were combined to categorize implementation level: the TCM was considered fully implemented, PTSD and PC were grouped as partially implemented, and MHA had no implementation.

\section{Interviews and focus groups \\ Knowledge about and acceptability of using eScreening}

Perceived fit Nearly all participants used optimistic language in anticipation of the new electronic tool that would replace paper screening.

It will be helpful in terms of streamlining the process for veterans - and for staff to do the more mundane administrative tasks that we have to do. (PreImplementation).

Most participants perceived the goals for eScreening as patient-centered. They believed it would be distinctly superior to collecting veterans' health information on paper because of the ability to quickly identify problem 
areas and initiate treatment for veterans. eScreening was seen as particularly valuable in emergency situations requiring swift interventions, such as suicidal patients.

Participants also believed that eScreening would aid the integrity of the information collected from veterans. A few participants said that veterans would receive more personalized care because eScreening will capture baseline information upon entry into the VA system, important demographics, and offer the medical providers big-picture data that can be trended over time.

I think it can help identify sets of problems that might not otherwise be detected through face-to-face interviews - but where the patient might get beneficial treatment. I think eventually it can lead to more personalized care where we could individualize their treatment plan a bit more based on the pattern of responses. (Pre-Implementation).

Post-implementation perspectives on the perceived fit of eScreening varied according to the amount of implementation. The MHA clinic staff, which never implemented eScreening, were concerned about the severity of psychiatric symptoms exhibited by veterans attending their clinic interfering with data collection, the possible negative effect of eScreening on the clinical encounter, and the feasibility to use eScreening in the context of the rapidly growing volume of veterans served. Participants believed that an eScreening program would be a poor fit for a MHA clinic because it serves as triage for "gravely disabled, suicidal, and homicidal" veterans that is more appropriately done through a faceto-face appointment.

It's not advisable for our emergency clinic because our numbers are going up for various reasons and to implement a new tool, it's not the right time. We used to see at most 25 veterans in our clinic per day; now we can see upwards of 40. To implement a new tool without someone in charge of it, I don't think that's feasible. If it populates, I need to see [the patient] right away and it makes me responsible; what if this guy said on [the iPad] that 'I am suicidal?' it's important to have that face-to-face conversation.

(Post-Implementation, MHA Clinic Provider).

Another disadvantage described by participants was the interference of data entry by the veteran during the clinical encounter. Staff in primary care also noted that the inconsistent use of eScreening among veterans did not result in a clinic-wide benefit of the technology.

We don't use it enough to say that [it helps track the patient's care any better]. I don't think above and beyond what the information that would have been garnered if my LVN or myself had done the clinical reminder. (Post-Implementation, PC Clinic Provider).

Relative advantages and impact Prior to implementation, many staff participants predicted eScreening's usefulness in tracking trends that could improve the VA healthcare system over the long term.

To expedite accessing care. If patients are putting in mental health concerns and they're screening positive, then those get in quickly, consults are quickly referred, etc. I think it's an impetus for looking at patterns and trends to see some of the problem areas. (Pre-Implementation).

It's quicker. It expedites a patient's ability to get assessed by somebody - to get linked with the services that they need. (Pre-Implementation).

Following implementation, eScreening was considered to have a positive impact in the delivery of clinical care In the TCM clinic. The other clinics viewed the impact of eScreening as mixed. Triaging care and the efficiency of data capture were the most prominent positive aspects of eScreening reported. Real time information, ease of use, and increased completion rates were also mentioned as benefits of eScreening.

eScreening's ability to triage care in the TMC clinic was described as a significant advantage. Participants noted that the rapid turnaround of information meant that veterans who need immediate care could get the services they needed. Staff stated:

I think it gives us real time information for veteran care on suicidality or homicidality, and so we can act on that. If we're not available, the folks in enrollment member services are excellent at helping someone get to the services they need. (Post-Implementation, TCM Clinic Provider).

Privacy One important concern staff had prior to the implementation of eScreening involved privacy for veterans to complete eScreening. Concerns regarding the storage of the tablet devices were also raised.

I worry about privacy. If they do it in the waiting room it can sometimes get fairly crowded. If they are sitting next to another patient, wedged in between other patients, I don't know if they are going to want to answer all of these potentially sensitive questions if somebody is looking over their shoulder.

(Pre-Implementation). 
Where are we going to keep them? That's the biggest challenge right there in my clinic. Where am I going to charge them? (Pre-Implementation).

Concern about privacy were also noted post-implementation. Some staff reported that some patients were resistant to eScreening because they perceived it as impersonal or had concerns about the privacy of their electronic information.

..., we have a lot of younger vets who don't want to use it because they think that the government is going to steal their information. A lot of people think it's impersonal. A lot of our veterans actually prefer the face-to-face contact with a nurse going through the questions - and not answering them on their own. It's not the ethos of the VA to just say to the veterans 'Do it.' (Post-Implementation, PC Clinic Provider).

Logistics/workflow Implementation of eScreening not only required the introduction of technology into the clinics, but it also altered the logistics of the check-in processes and work flow. Both benefits and challenges were reported. Some clinics' staff found it possible for veterans to complete the screening process with little or no assistance while waiting for an appointment, and they noted that having the information available for the provider was an efficient use of time.

Usually if they're in the office and I'm doing enrollment, they are completing it across from me. They may ask a couple of questions and I can usually help them with it. We give them the tablet while they're waiting for their name to be called for registration. It works out like that. It really works as a filler because we have upwards of sometimes an hour wait for enrollment.

(Post-Implementation, TCM Clinic Provider)

It was noted in other clinics, however, achieving this efficiency would require that patients arrive early for appointments and that some assistance would be occasionally needed. It was clear that having the provider assist the veterans with data entry mitigated the efficiency advantage of eScreening.

I think the main challenge has always been the logistics of how you get the tool into the hands of patients in terms of how the patients arrive, the sequencing of their visit. So my sense has been that technology is probably pretty straightforward, but the processes that support it in deploying it to patients is more challenging. (Post-Implementation, PC Clinic Provider).
I had hoped that there would be better uptake of it by the patients, but it did kind of point out to me that over half of my patients arrive either just on time, a few minutes late, or significantly late for their appointment. So at least over 50\% were not offered e-screening, as a result. (Post-Implementation, PC Clinic Provider).

\section{Usability of eScreening}

Functionalities Some focus group participants expressed concern that length of screening could be a barrier to the implementation of eScreening and that a shorter personalized set of screens for each veteran's needs might facilitate success. Others expressed concerns about confidentiality.

The frustrations for veterans might be that it's a burdensome process where we have them doing too many measures - that might make it unsuccessful. One thing that would make it successful is not having it be a burden - having the assessment individualized, i.e. if we have a reason to administer a measure for a certain patient, then we select that measure, but not having every patient do twenty measures.

(Pre-Implementation).

The capabilities of the eScreening program were viewed positively across most participants in those clinics with at least partial implementation. The ability to customize the assessments, visually display data, and complete clinical reminders were some of the features that were favorably viewed. Staff recognized the efficiency of patient-entered data.

I think it's been really helpful to me is that the eScreening is set up so that it will also have the patient do clinical reminders. And I will so often forget to do those. I actually get feedback -- it says, 'good utilization of clinical reminders.' So that helps me in terms of my evaluation for work and efficiency. That makes it a lot easier. (Post-Implementation, PTSD Clinic Provider).

The tailoring of the assessment to the needs of the clinic and the efficiency of data capture was noted by several of the clinics' staff.

The OEF/OIF screen which is a battery of symptoms that are totally not related to what you're necessarily having the visit for. And so to have that completed in advance actually frees up a fair amount of clinic time in that visit. (Post-Implementation, PC Clinic Provider). 
Personal characteristics of veterans Concerns about the usability of eScreening with older veterans and those with certain physical impairments were brought up during both pre- and post-implementation interviews. Participants believed that those most familiar with technology and digital devices, younger veterans, would have fewer problems with eScreening and will likely embrace it. Nearly all participants expressed concern about older veterans or patients of any age who are visually or physically challenged.

Some of the younger veterans seem to really like it and I think just even knowing that we're starting to integrate technology showcases that we're actually keeping up to date. Something about that that creates a message that our healthcare is partially on the cutting edge, as opposed to here is some printed out piece of paper. (Post-Implementation, PTSD Clinic Provider).

We have some patients who are quite elderly and who really don't have the skills to be able to do it without your reading it to them for whatever reason disabilities they're dealing with at the time or they just don't understand how it works and they're punching buttons and they don't get it. There might just be some people that we can't really integrate in and that's $O K$. (Post-Implementation, PTSD Clinic Provider).

Technology-related problems Some staff noted that communication with the VA check-in kiosks would need to be addressed before eScreening could be fully implemented.

The kiosk and the eScreening do not communicate; that needs to be addressed. We have patients who don't' want to stand in line or they're late for their appointment and in a rush so they just go to the kiosk and that's how we are going to miss them for eScreening. (Post-Implementation, PC Clinic Provider).

Although there were some technical issues related to the computer tablets, internet connectivity and communication among existing electronic medical records, postimplementation interviews noted that technical assistance was readily available and that issues were quickly resolved.

Facilitators and barriers to the successful implementation of eScreening (including system and organizational readiness and resources)

Introduction and training Participants were largely satisfied with the introduction and training that was provided. They also found the technical support adequate.
Everyone got individualized training. When I had any follow-up questions, [name] was very responsive, as well. (Post-Implementation, PTSD Clinic Provider).

However, the introduction process of eScreening varied among clinics. In particular, some staff noted that the length of time between the training on eScreening and the launch of the program was crucial to successful implementation. In those clinics where there was a long lag between training and introduction of eScreening (PC and MHA Clinics), implementation was incomplete.

The overall buy-in was harder because, coincidentally, the teams were changing significantly throughout the process of the rollout. Those initial meetings were a really long time ago -- like 2 years ago.

(Post-Implementation, PC Clinic Provider).

Openness to change Openness to change was identified as a facilitator for implementation by focus group participants. The TCM clinic noted that they had prepared their team for the changes associated with the implementation of eScreening.

I was originally resistant - thought it would be extra work because the iPad would be a challenge for some of our veterans and they would come up and ask questions. So I was a little standoffish at first. Once we got it off the ground, I was able to see the ease of the program itself and the use of the tablet. In fact, I have some thoughts about expanding some of the usage possibilities.

(Post-Implementation, TCM Clinic Provider).

The two clinics with partial implementation (PTSD and PC Clinics) noted some resistance was present in some staff.

Obviously, I think part of the problem is, of course, change.

The MHA clinic expressed the least openness to eScreening.

The entire idea of turning all of mental health into a screening process is a very VA-oriented type of thinking and is, in and of itself, flawed. When they try to elaborate it with these different tools and electronics and notes and documentation, you're just compounding what was already a flawed idea in the first place. It may work in other specialties; I'm open to that, but not in mental health. (Post-Implementation, MHA clinic staff). 
Resources and leadership support When asked to anticipate what types of barriers may hinder the integration of eScreening into their clinics, some focus group participants predicted the need to hire personnel.

The personnel available to administer the screens is key... I think that's the piece that is still a little tricky. We need someone to always be there to administer the screeners when they need to be administered; otherwise we'll go back to the old paper way which really takes up more time. (Pre-Implementation).

\section{I think it's going to be difficult. The set-up is} dysfunctional. If the patient has difficulty with the escreening, they're going to take the iPad and get back on that line to ask the clerks which is going to slow things down even more. (Pre-Implementation).

Most staff agreed that with adequate resources and work flow modification, the use of eScreening would benefit veterans.

I see a lot of potential for it being a really excellent and official tool. So I would be supportive if it was used throughout the hospital and throughout the VA, then these things would need to fall into place - and they would. It's going be a standard of care.

(Post-Implementation, PTSD Clinic).

I don't know that I would find it beneficial to continue $i t$. There are options to be creative with it and if we can find a way where it benefits everyone's workload, then I would be in favor of continuing it.

(Post-Implementation, PC Clinic).

Though most leadership expressed strong support for eSceeening in individual interviews, many staff focus group participants sensed a lack of enthusiasm for the project either because of little to no communication from the top.

I haven't heard anything from my supervisor regarding eScreening tablets so I assume he knows. Maybe he's on board; it just wasn't communicated to us.

(Pre-Implementation).

An apparent relationship between degree of eScreening implementation and leadership engagement was noted. The TCM clinic was clearly aware of leadership support for the use of eScreening. In both the PC and PTSD clinics, which had partial implementation, there was confusion about leadership engagement. Moreover, some participants felt that there was insufficient accountability for the implementation of eScreening that affected its successful adoption.

There are no consequences for not using eScreening. I would have no idea if my $L V N$ was offering it. I have no idea if the AMSA's up front are doing it. I feel like I'm cut off from the process a little bit. If it happens, it's without my input. (Post-Implementation, PC Clinic).

Length of screening, confidentiality, and logistical concerns The physical layout of the clinics also presented some logistical challenges. Different designated spaces for check-in and waiting areas generated difficulty with the efficient use of eScreening.

There is definitely a space problem. We have a lot of confusion. We shouldn't have to walk down the hall, walk back down the hall - there is not enough space for the people in the front line to take care of the patients' needs and the eScreening. We have two computers and most days we have 15-20 people nonstop for hours as walk-ins. (Post-Implementation, PC Clinic)

Other barriers to the use of eScreening related to the diverse demographic and clinical characteristics of veterans served and to inadequate staffing to oversee the distribution of, interaction with, and collection of the computer tablets.

I think La Jolla primary care clinic has been particularly challenging just because of our demographics. We get the sickest, the worst behaved, the oldest patients, and the walk-ins.

(Post-Implementation, PC Clinic).

Pre- post- implementation similarities and differences Impressions about eScreening were mostly positive at pre- and post- implementation, although some concerns related to adequate resources, changes to workflow, technical difficulties, and privacy were expressed at both time points. The impact of eScreening on clinical care was perceived as largely positive at pre-implementation, but was mixed at post-implementation for the clinics that had partial or no implementation. Concerns about the usability of eScreening with older veterans and those with certain physical impairments were brought up during both pre- and post-implementation interviews. However, at post-implementation, it was also noted that some younger veterans expressed concerns about privacy and the impersonal nature of computerized assessment. Prior to implementation, staff perceived a lack of 
leadership support and communication regarding eScreening. At post-implementation, the clinics with partial or no implementation also described less leadership support and engagement.

Most participants were open to using eScreening at preimplementation. However, during post-implementation interviews, there was more resistance to change in the clinics with partial or no implementation. Training was described as a facilitator for the implementation of eScreening at both time points. Perceived barriers at pre-implementation included concerns such as the length of the assessment, privacy, and device storage. Post-implementation barriers for some included the timing of the training (e.g., extended time between training and actual implementation of eScreening), inadequate resources, changes to workflow, certain veteran characteristics (e.g., acute patients), and a few technological challenges.

\section{Survey results}

Three of the four clinics reported Engagement and Satisfaction scores above the 50th percentile relative to the Gallup's 2016 US Government Workgroup-Level Database. The MHA clinic scored in the lower quartile for both Engagement and Satisfaction (Fig. 1).

On the individual items of the $\mathrm{Q} 12^{\circ}$ Index, the TCM and PTSD clinics scored well above the 50th percentile range on nearly all the items, compared to Gallup's 2016 US Government Workgroup-Level Database. Most of the $\mathrm{Q} 12^{\circ}$ individual items for the $\mathrm{PC}$ clinic were above the 50th percentile. However, the participants from the MHA clinic scored under the 25th percentile on several items related to individual and teamwork engagement factors (see Fig. 2).

Results of the post-implementation eScreening survey indicated that the TCM, PC, and PTSD clinics positively viewed the implementation of eScreening (See Table 2). There were no differences in the clinics' views that eScreening improves healthcare, and they were equally likely to continue it as well as recommend it.

\section{Integration of qualitative and quantitative findings}

Clinics with higher scores on the quantitative measures showed more positive attitude toward the implementation of eScreening in the qualitative interviews. The TCM clinic, which had the highest level of eScreening implementation/usage, had the most positive attitude toward the implementation of eScreening both in the quantitative and qualitative assessments. In contrast, the MHA clinic, which did not implement eScreening, demonstrated the lowest scores and least positive attitudes toward the implementation of eScreening on both quantitative and qualitative measures. Results are summarized in Table 3.

\section{Discussion}

The purpose of this mixed method, quasi-experimental quality improvement project of the evaluation of eScreening implementation in four VA clinics was to gather information on: (1) implementation of eScreening; (2) knowledge about and acceptability, perceived fit/adaptability, and relative advantage of using eScreening; (3) usability of eScreening; and (4) facilitators and barriers

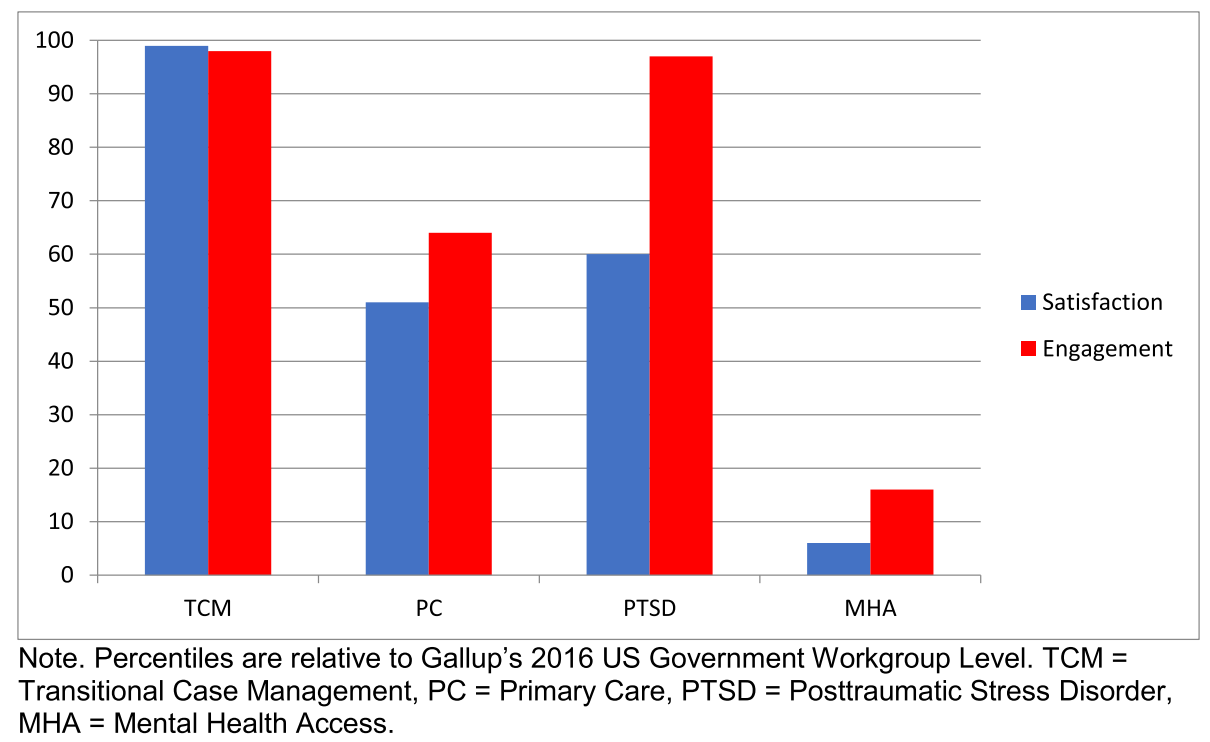

Fig. 1 Satisfaction and Engagement scores from the Q12 ${ }^{\circledR}$ by VA clinic. Graph of percentiles of Satisfaction and Engagement scores from the Q12 ${ }^{\circledR}$ for each VASDHS clinic relative to Gallup's 2016 US Government Workgroup Level 


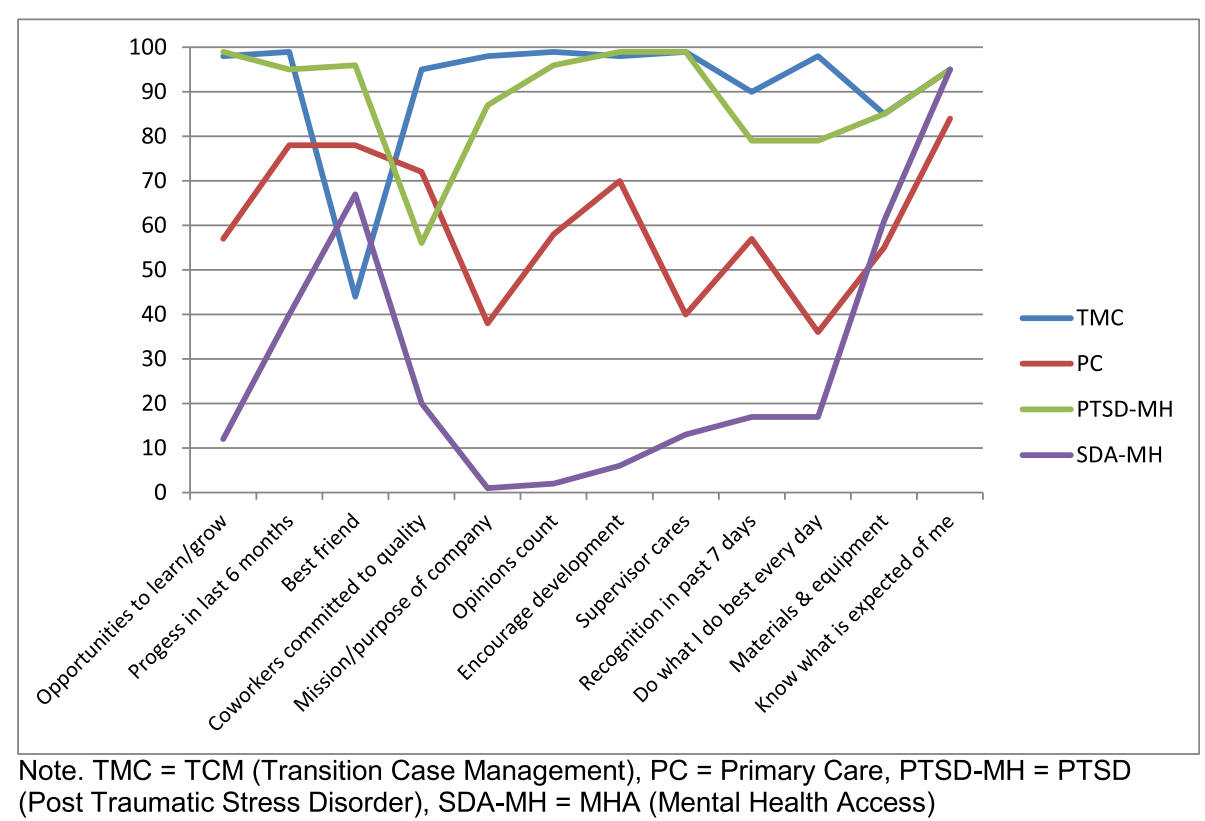

Fig. 2 Percentile rankings of individual $\mathrm{Q} 12^{\circledR}$ items by VA clinic. Graph of percentile rankings for each of the 12 individual $\mathrm{Q} 12^{\circledR}$ items by VASDHS clinic

to successful implementation of eScreening, including system and organizational readiness and resources.

Results showed that implementation was variable: one clinic was successful, two were partially successful, and one was unsuccessful. Survey data on worker satisfaction and engagement, as well as readiness to change, paralleled the degree of implementation. A convergence of both quantitative and qualitative data indicated that openness to change, leadership engagement and accountability, and work flow and sufficient staff and space had a significant influence on the implementation of eScreening. The role of these internal context-related variables in facilitating or impeding implementation of evidence-based interventions has been shown broadly in the literature and more specifically in the context of the VA [40].
Knowledge on and acceptability of eScreening were generally positive. Qualitative data revealed that participants saw the clinical benefit of eScreening: the ability to triage care, capture and track clinical data efficiently and accurately, and meet reporting requirements. However, some concerns about changes to workflow were raised. In addition, at post-implementation, some concerns about fit for some populations and interference of eScreening with the clinical encounter emerged. Another concern raised by staff participants regarding the implementation of eScreening was the acuity/severity of psychiatric symptoms. The MHA clinic reported that eScreening was not a good fit for veterans with significant psychiatric symptoms. The appropriateness of computerized assessment clearly needs to be considered and weighed against the purpose of information collection

Table 2 Means and standard deviations from the escreening Survey by clinic

\begin{tabular}{|c|c|c|c|c|}
\hline & TCM & PC & PTSD & MHA \\
\hline Confidence in facility leadership to manage challenges & $3.6(.89)$ & $2.7(1.19)$ & $3.8(.84)$ & $2.0(1.41)$ \\
\hline Able to adapt when changes occur that affect my job & $4.2(.84)$ & $4.2(.94)$ & $4.4(.55)$ & $2.8(1.50)$ \\
\hline Received the training necessary & $4.8(.45)$ & $4.1(1.80)$ & $4.6(.55)$ & * \\
\hline Technical issues were resolved quickly & $4.8(.45)$ & $3.8(.90)$ & $4.6(.55)$ & * \\
\hline Implementation improves healthcare that Veterans receive & $4.6(.56)$ & $3.8(1.13)$ & $4.4(.55)$ & * \\
\hline Satisfied with eScreening implementation process & $4.6(.56)$ & $3.1(1.41)$ & $4.4(.55)$ & * \\
\hline Recommends the use of eScreening for all Veterans & $4.8(.45)$ & $3.5(1.47)$ & $3.8(1.10)$ & * \\
\hline There are significant barriers to implementing ${ }^{* *}$ & $3.0(1.58)$ & $3.1(1.39)$ & $2.8(1.26)$ & * \\
\hline Use eScreening in the clinic & $4.5(.58)$ & $3.6(1.15)$ & $3.8(.84)$ & * \\
\hline
\end{tabular}

Note. *too few to score ** reversed scoring 
Table 3 Qualitative and Quantitative Results

\begin{tabular}{|c|c|c|c|c|c|}
\hline Data & Type & TCM & PTSD & PC & $\mathrm{MHA}$ \\
\hline Pre & Qualitative & Positive & Mixed & Mixed & Mixed \\
\hline Post & Qualitative & Positive & Mostly positive & Mixed & Negative \\
\hline Survey & Quantitative & & & & \\
\hline Q12® Satisfaction & & $>$ >5\%tile & $>50 \%$ tile & $>50 \%$ tile & $<10 \%$ tile \\
\hline Q12 Engagement & & $>95 \%$ tile & $>95 \%$ tile & $>60 \%$ tile & $<25 \%$ tile \\
\hline escreening & & Positive & Mixed & Positive & Negative/missing \\
\hline Usage & Quantitative & Full & Partial & Partial & None \\
\hline
\end{tabular}

for every clinic. Comprehensive screening may not be appropriate in urgent care clinics, as the MHA clinic staff commented, but brief symptom measures may be feasible. This differs from studies that have reported successful implementation of computer assisted assessments in those with severe mental illness and opioid users in the emergency department $[8,41]$.

Quantitative and qualitative data on usability were also generally positive. A strength of eScreening may be its flexibility in the type of information gathered. It is not an off-the-shelf system, but, rather, it is tailored to the needs of the clinic and has been developed iteratively with input from multiple stakeholder and user groups. Involvement of stakeholders in the design and development of HIT has been found to be crucial in its implementation [42]. We found that engaging providers early in the configuration of the data capture appeared to be an important component of the implementation of eScreening.

Aspects of the technology presented few challenges related to the usability and implementation of eScreening, as seen in both survey results and focus group and individual interviews. The general lack of technology-related problems may be a function of the growing familiarity of HIT both in and out of the VA, as well as the improved infrastructure and support for various technologies. Notably, while technology presented few difficulties in implementation, one exception was with older veterans and those with certain disabilities that made using eScreening difficult. Other VA studies of healthcare technology have found that both older and younger veterans easily engaged with technology, but strongly emphasize that HIT should have user-friendly features and be intuitive [29]. Although some staff participants believed that the integration of technology into healthcare delivery was inevitable and that veteran users would need to accept it, accessibility issues continue to be an important aspect of usability, and consequently, adoption. Coincidentally, VA is adopting human-centered design in the development of HIT, and researchers have found that veterans preferred standardized, integrated, and synchronized interface designs [29]. Continued input from providers and veterans regarding functions and capabilities, as well as usability of eScreening is important and appears to be instrumental in its implementation.

Facilitators of eScreening implementation included higher workplace engagement, preparation for change, and perceived leadership support. Conversely, perceived lack of leadership support and accountability, patient screening burden, physical location, and lack of personnel support were barriers. Several other factors appeared to be related with eScreening implementation. These encompassed barriers associated with the veterans, including demographic characteristics, such as age, and other medical and clinical factors like dexterity, visual acuity and severity of psychiatric symptoms. Like other studies of HIT, we found that staff reluctance to change was a barrier to the implementation $[34,36]$. The MHA clinic was particularly reluctant to change. However, this may have been due, in part, to the observation that they did not seem to realize the full value and potential of the tool. The more challenging issues of the implementation of eScreening in VA clinics related to staff and physical resources and work flow, a common problem observed with the introduction of HIT [34]. eScreening clearly impacted work flow, so team approach for its implementation is important, as was demonstrated by the TCM team. Workload may increase for some members of the team, so it is important that benefits are communicated to all team members.

This study has several methodological characteristics common with quality improvement projects that challenge internal validity, such as the lack of a control condition, samples of convenience, and variation in the implementation strategy. Generalizability of these findings is limited to the sites similar to those of the current study. Clinics were not randomly selected, and, as noted from the focus group and interview data, there was no accountability for the providers to implement eScreening, thus leading to selection bias. Another limitation of the study is the inability to determine the percent and representativeness of veterans reached in each clinic because data on patient volume was not collected. The implementation strategies used in this study are well established [43], but they were not theoretically informed 
by a particular framework or theory and we did not collect information on the amount of technical assistance provided to each clinic. The pre-implementation quotes were organized by Gallup by CFIR construct only, so we were unable to attribute them to a specific clinic. Finally, the VA is a fully integrated healthcare system where employees have clear incentives to adhere to organizational policies in contrast to different systems where physicians are not employees. As a next step, our team will use information from the work presented in this paper and will develop a multi-component implementation strategy that will build on the improvement science methodology.

\section{Conclusions}

This study is one of the first to use a mixed method design to assess the implementation of a computer assisted assessment system in the VA healthcare system. Although this study was a quality improvement project, the triangulation of quantitative and qualitative data strengthens credibility of results.

Perhaps the most studied example of the implementation of HIT to date is the electronic medical record (EMR), and reviews of the case studies of successes and failures of EMR implementation have highlighted the importance of context, both organizational and social factors [44]. Several frameworks have been described socio-technology theories, contextual implementation model, triangle evaluation model - that all include multilevel factors such as "macro", "micro", and individual levels of influences very similar to dissemination and implementation frameworks used to guide implementation of clinical guidelines or evidence-based practices.

Despite some added work load for some staff and perceived lack of leadership support, eScreening was at least partially implemented in three of the clinics. The technology itself posed no barriers in any of the settings. An implementation strategy that that includes a strong communication and training/technical assistance plan, accounts for increased work burden and changes to work flow, and sets accountability expectations may help future eScreening implementation efforts. It may also be important to address engagement and change management for employees as part of implementation efforts, which can be accomplished through approaches such as the Lean Six Sigma Rapid Process Improvement Workshop.

\section{Additional files}

Additional file 1: Pre-implementation Leadership Interview. (DOCX 34 kb) Additional file 2: Pre-impllementation Focus Group Interview. (DOCX $34 \mathrm{~kb})$

Additional file 3: Post-implementation Focus Group Interview. (DOCX $37 \mathrm{~kb})$
Additional file 4: Post-implementation Leaderhip Interview. (DOCX 35 kb)

\section{Abbreviations}

CESAMH: The VA Center of Excellence for Stress and Mental Health; CFIR: Consolidated Framework for Implementation Research; EMR: Electronic Medical Record; HIT: Health Information Technology; MHA: Mental Health Access; PC: Primary Care; PCL-5: Posttraumatic Stress Disorder Checklist; PTSD: Posttraumatic Stress Disorder; Q12: Gallup Employee Engagement Survey; QIP: Quality Improvement Project; TB-SA: Technology-Based SelfAssessment; TCM: Transition Care Management; VA: Veterans Administration; VACl: VA Center for Innovation; VASDHS: VA San Diego Healthcare System

\section{Acknowledgements}

We thank Michael Kilmer, Kym Grey, Natasha Schwartz, Jesse Christmas, Darryl Simmons, Emmanuel Carter, Daniel Tang, Melinda Lee, Laura Owen, Christina Zeitountsyan, Christine Edwards, Nazia Hossain, Andrew De La Rosa, Edward Gause, Robert Earnest, Ryan Wong, Matthew Morgan, Clint Latimer, and Heather Donovan for their support and diligent work on this project.

\section{Authors' contributions}

JP contributed to the project design, development of the measures, data interpretation, drafting and revising the manuscript. NA participated in the design and coordination and contributed to drafting/revising the manuscript. EF assisted with data collection, analysis, and drafting of the manuscript. EA contributed to drafting the results and discussion sections and the manuscript revisions. SC was involved with development of interview guide, data collection, data analysis, and the data analysis section of the methods. BR participated in data analysis and interpretation, and development/revision of the manuscript. LL was the senior contributing author, participated in the design and coordination, and helped with data interpretation and drafting/ revising the manuscript. All authors read and approved the final manuscript.

\section{Funding}

This project was funded by the Veterans Affairs Center for Innovation (VACI) and had no role in the design; collection, analysis, and interpretation of data; or writing the manuscript. The project and authors were also supported by the VA Center of Excellence for Stress and Mental Health (CESAMH) who were involved in the design; collection, analysis, and interpretation of data; and writing the manuscript as stated below. This material also is the result of work supported with resources of the VA San Diego Healthcare System. The views expressed in this paper are those of the authors and do not reflect the official policy or position of the Department of Veteran Affairs or any of the institutions with which the authors are affiliated.

\section{Availability of data and materials}

The datasets supporting the conclusions of this article are available available from the corresponding author on reasonable request.

\section{Ethics approval and consent to participate}

This project was retrospectively reviewed by the Institutional Review Board (IRB) at the VA San Diego Healthcare System (protocol reference HRD180077) and deemed not research because the work was originally completed as a quality improvement project (QIP) prior to developing a manuscript. Since this project was originally conducted as a QIP and the results were deidentified and aggregated by setting, written consent was not required. All participants were notified of the project's purpose and need to audio record. Confidentiality agreement and verbal assent was given by each participant. Since the project was deemed not research, IRB review of these procedures was not necessary.

Consent for publication

Not Applicable.

\section{Competing interests}

The authors declare that they have no competing interests.

\section{Author details}

${ }^{1} V A$ Center of Excellence for Stress and Mental Health, 3350 La Jolla Village Dr., San Diego, CA 92161, USA. ²Department of Psychiatry, University of California San Diego, 9500 Gilman Dr, La Jolla, CA 92093, USA. ${ }^{3}$ VA Roseburg Health Care System, 913 NW Garden Valley Blvd, Roseburg, OR 97470, USA. 
${ }^{4}$ Gallup Inc., 901 F Street, NW, Washington, DC 20004, USA. ${ }^{5}$ Department of Family Medicine and Public Health, University of California San Diego, 9500 Gilman Dr, La Jolla, CA 92093, USA.

Received: 5 March 2019 Accepted: 16 August 2019

Published online: 28 August 2019

\section{References}

1. Shekelle P. Morton S, Keeler E. Costs and benefits of health information technology. Evidence report/technology assessment no. 132. (prepared by the Southern California evidence-based practice center under contract no. 290-02-0003.) AHRQ publication no. 06-E006. Rockville, MD: Agency for Healthcare Research and Quality. April 2006.

2. Yen P, McAlearney A, Sieck C, Hefner J, Huerta T. Health information technology (HIT) adaptation: refocusing on the journey to successful HIT implementation. JMIR Med Inform. 2017:5(3):e28

3. Brenner S, Kaushal R, Grinspan Z, Joyce C, Kim I, Allard R, et al. Effects of health information technology on patient outcomes: a systematic review. J Am Med Inform Assoc. 2015;23(5):1016-36.

4. Aktas A, Hullihen B, Shrotriya S, Thomas S, Walsh D, Estfan B. Connected Health: Cancer Symptom and Quality-of-Life Assessment Using a Tablet Computer. American Journal of Hospice and Palliative Medicine ${ }^{\oplus}$. 2013;32(2):189-197.

5. Hjermstad M, Lie H, Caraceni A, Currow D, Fainsinger R, Gundersen O, et al. Computer-based symptom assessment is feasible in patients with advanced Cancer: results from an international multicenter study, the EPCRC-CSA. J Pain Symptom Manag. 2012;44(5):639-54.

6. Rayner L, Matcham F, Hutton J, Stringer C, Dobson J, Steer S, et al. Embedding integrated mental health assessment and management in general hospital settings: feasibility, acceptability and the prevalence of common mental disorder. Gen Hosp Psychiatry. 2014;36(3):318-24.

7. Stukenborg G, Blackhall L, Harrison J, Barclay J, Dillon P, Davis M, et al. Cancer patient-reported outcomes assessment using wireless touch screen tablet computers. Qual Life Res. 2013;23(5):1603-7.

8. Weiner S, Horton L, Green T, Butler S. Feasibility of tablet computer screening for opioid abuse in the emergency department. West J Emerg Med. 2015:16(1):18-23.

9. Algilani S, Langius-Eklöf A, Kihlgren A, Blomberg K. An interactive ICT platform for early assessment and management of patient-reported concerns among older adults living in ordinary housing - development and feasibility. J Clin Nurs. 2017:26(11-12):1575-83.

10. Brinkman S, Reese R, Norsworthy L, Dellaria D, Kinkade J, Benge J, et al. Validation of a self-administered computerized system to detect cognitive impairment in older adults. J Appl Gerontol. 2012;33(8):942-62.

11. Fanning J, McAuley E. A comparison of tablet computer and paper-based questionnaires in healthy aging research. JMIR Research Protocols. 2014;3(3):e38.

12. Kingston D, Austin M, Veldhuyzen van Zanten S, Harvalik P, Giallo R, Mc Donald S, et al. Pregnant Women's Views on the Feasibility and Acceptability of Web-Based Mental Health E-Screening Versus Paper-Based Screening: A Randomized Controlled Trial. J Med Internet Res. 2017;19(4):e88.

13. Bradford S, Rickwood D. Acceptability and utility of an electronic psychosocial assessment (myAssessment) to increase self-disclosure in youth mental healthcare: a quasi-experimental study. BMC Psychiatry. 2015;15:1.

14. Fann J, Hong F, Halpenny B, Blonquist T, Berry D. Psychosocial outcomes of an electronic self-report assessment and self-care intervention for patients with cancer: a randomized controlled trial. Psycho-Oncology. 2016:26(11):1866-71

15. Faurholt-Jepsen M, Munkholm K, Frost M, Bardram J, Kessing L. Electronic self-monitoring of mood using IT platforms in adult patients with bipolar disorder: A systematic review of the validity and evidence. BMC Psychiatry. 2016:16:1.

16. Haskins B, Davis-Martin R, Abar B, Baumann B, Harralson T, Boudreaux E. Health evaluation and referral assistant: a randomized controlled trial of a web-based screening, brief intervention, and referral to treatment system to reduce risky alcohol use among emergency department patients. J Med Internet Res. 2017:19(5):e119.

17. Tolley C, Rofail D, Gater A, Lalonde J. The feasibility of using electronic clinical outcome assessments in people with schizophrenia and their informal caregivers. Patient Related Outcome Measures. 2015;6:91-101.
18. Diaz V, Mainous A, Gavin J, Player M, Wright R. Use of a tablet-based risk assessment program to improve health counseling and patient-provider relationships in a federally qualified health center. Am J Med Qual. 2016;31(5):434-40.

19. Fleischmann R, Decker A, Kraft A, Mai K, Schmidt S. Mobile electronic versus paper case report forms in clinical trials: a randomized controlled trial. BMC Med Res Methodol. 2017;17:1.

20. Imani G, Barrios C, Anderson C, Hosseini Farahabadi M, Banimahd F, Chakravarthy B, et al. Computerized alcohol screening identified more atrisk drinkers in a level 2 than a level 1 trauma center. BMC Public Health. 2017:17:1.

21. Jensen R, Snyder C, Abernethy A, Basch E, Potosky A, Roberts A, et al. Review of electronic patient-reported outcomes systems used in Cancer clinical care. Journal of Oncology Practice. 2014;10(4):e215-22.

22. Jensen S, Borycki E. Clinical simulation in the development of ehealth: insitu and laboratory simulation. Studies in Health Technology and Informatics. 2016;225:247-51.

23. Pittman J, Floto E, Lindamer L, Baker D, Lohr J, Afari N. The VA eScreening program: technology to improve care for post-9/11 veterans. Psychol Serv. 2017;14(1):23-33.

24. Schick-Makaroff K, Molzahn A. Strategies to use tablet computers for collection of electronic patient-reported outcomes. Health Qual Life Outcomes. 2015;13(1):2.

25. Wagner L, Schink J, Bass M, Patel S, Diaz M, Rothrock N, et al. Bringing PROMIS to practice: brief and precise symptom screening in ambulatory cancer care. Cancer. 2014;121(6):927-34.

26. Wintner L, Giesinger J, Zabernigg A, Rumpold G, Sztankay M, Oberguggenberger $\mathrm{A}$, et al. Evaluation of electronic patient-reported outcome assessment with cancer patients in the hospital and at home. BMC Medical Informatics and Decision Making. 2015;15:1.

27. Department of Veteran's Affairs. VA annual benefits report. Retrieved from http://www.va.gov/op3/docs/StrategicPlanning/NA2014-2020strategicPlan. PDF. 2013.

28. Bradley S, Rumsfeld J, Ho P. Incorporating health status in routine care to improve health care value. JAMA. 2016;316(5):487.

29. Haun J, Chavez M, Nazi K, Antinori N, Melillo C, Cotner B, et al. Veterans' preferences for exchanging information using veterans affairs health information technologies: focus group results and modeling simulations. J Med Internet Res. 2017;19(10):e359.

30. Klein D, Fix G, Hogan T, Simon S, Nazi K, Turvey C. Use of the Blue button online tool for sharing health information: qualitative interviews with patients and providers. J Med Internet Res. 2015;17(8):e199.

31. Kuhn E, Weiss B, Taylor K, Hoffman J, Ramsey K, Manber R, et al. CBT-I coach: a description and clinician perceptions of a Mobile app for cognitive behavioral therapy for insomnia. J Clin Sleep Med. 2016;12(04):597-606.

32. Tew J, Klaus J, Oslin D. The behavioral health laboratory: building a stronger foundation for the patient-centered medical home. Fam Syst Health. 2010;28(2):130-45

33. Woods S, Schwartz E, Tuepker A, Press N, Nazi K, Turvey C, et al. Patient experiences with full electronic access to health records and clinical notes through the my HealtheVet personal health record pilot: qualitative study. J Med Internet Res. 2013;15(3):e65.

34. Boonstra A, Versluis A, Vos J. Implementing electronic health records in hospitals: a systematic literature review. BMC Health Serv Res. 2014;14:1.

35. Kruse C, Kristof C, Jones B, Mitchell E, Martinez A. Barriers to Electronic Health Record Adoption: a Systematic Literature Review. J Med Syst. 2016:40:12.

36. Simon S, Keohane C, Amato M, Coffey M, Cadet B, Zimlichman E, et al. Lessons learned from implementation of computerized provider order entry in 5 community hospitals: a qualitative study. BMC Medical Informatics and Decision Making. 2013;13:1

37. Takian A, Sheikh A, Barber N. We are bitter, but we are better off: case study of the implementation of an electronic health record system into a mental health hospital in England. BMC Health Serv Res. 2012;12:1.

38. Damschroder L, Aron D, Keith R, Kirsh S, Alexander J, Lowery J. Fostering implementation of health services research findings into practice: a consolidated framework for advancing implementation science. Implement Sci. 2009;4:1.

39. Harter J, Schmidt F, Agrawal S, Plowman S, Blue A. The relationship between engagement at work and organizational outcomes. Gallup Poll Consulting University Press, Washington. 2016. 
40. Landes S, Rodriguez A, Smith B, Matthieu M, Trent L, Kemp J, et al. Barriers, facilitators, and benefits of implementation of dialectical behavior therapy in routine care: results from a national program evaluation survey in the veterans health administration. Transl Behav Med. 2017:7(4):832-44.

41. Chinman M, Young A, Schell T, Hassell J, Mintz J. Computer-assisted selfassessment in persons with severe mental illness. The Journal of Clinical Psychiatry. 2004;65(10):1343-51.

42. Kwan B, Sills M, Graham D, Hamer M, Fairclough D, Hammermeister K, et al. Stakeholder engagement in a patient-reported outcomes (PRO) measure implementation: a report from the SAFTINet practice-based research network (PBRN). The Journal of the American Board of Family Medicine. 2016;29(1):102-15.

43. Powell B, Waltz T, Chinman M, Damschroder L, Smith J, Matthieu M, et al. A refined compilation of implementation strategies: results from the Expert Recommendations for Implementing Change (ERIC) project. Implement Sci. 2015;10:1.

44. Kuziemsky C. Review of social and organizational issues in health information technology. Healthcare Informatics Research. 2015;21(3):152.

\section{Publisher's Note}

Springer Nature remains neutral with regard to jurisdictional claims in published maps and institutional affiliations.

Ready to submit your research? Choose BMC and benefit from:

- fast, convenient online submission

- thorough peer review by experienced researchers in your field

- rapid publication on acceptance

- support for research data, including large and complex data types

- gold Open Access which fosters wider collaboration and increased citations

- maximum visibility for your research: over $100 \mathrm{M}$ website views per year

At BMC, research is always in progress.

Learn more biomedcentral.com/submissions 